INDONESIAN MINING PROFESSIONALS JOURNAL

PERHAPI, Komplek Rukan Crown Palace Blok D. 09

J. Prof. Dr. Soepomo, SH No. 231, Tebet - Jakarta Selatan 12870

Telp : 021-83783766, Email : jurnal.perhapi@gmail.com

https://jurnal.perhapi.or.id/index.php/impj

\title{
PENENTUAN DESAIN CHAIN PILLAR PADA TAMBANG BATUBARA SHORTWALL MINING
}

\author{
Ratih Hardini Kusuma Putri ${ }^{1}$, Diana Irmawati Pradani ${ }^{2}$ \\ ${ }^{1}$ Prodi Teknik Pertambangan, Fakultas Teknologi Mineral\&Kelautan, Institut Teknologi Adhi Tama Surabaya \\ ${ }^{2}$ Prodi Teknik Pertambangan, Fakultas Teknik, Polinema, Malang, 65141
}

Artikel masuk : 24-03-2020, Artikel diterima : 06-09-2020

Kata kunci:

Shortwall mining, chain pillar, tambang batubara bawah tanah

Keywords:

Shortwall mining, chain pillar, underground coal mines

\begin{abstract}
ABSTRAK
Penambangan batubara dengan metode shortwall memiliki resiko terhadap keruntuhan atap lubang bukaan dan pilar batubara. Hal ini dipengaruhi oleh faktor kestabilan dari lubang bukaan dan juga pilar sebagai penyangga alamiah pada area penambangan. Dengan adanya permasalahan tersebut diperlukan suatu kajian geoteknik terhadap rancangan pilar batubara bawah tanah, agar kegiatan penambangan dapat dikerjakan dengan aman dan lancar. Penentuan desain lebar chain pillar dianalisis secara analitik. Penentuan desain lebar chain pillar dianalisis secara analitik. Data geometri seam $\mathrm{D}=9 \mathrm{~m}$, maka didapat ekstraksi rasio (nilai $\mathrm{r}$ ) sebesar $43,75 \%$ pada satu level penambangan. Jika berdasarkan hasil perhitungan lebar kritis chain pillar tiap levelnya didapat nilai ekstraksi rasio yaitu, seam $D=5,94$ $\mathrm{m}$, didapat ektraksi rasio (nilai $\mathrm{r}$ ) $=55,85 \%$.
\end{abstract}

\section{ABSTRACT}

Coal mining with the shortwall method has the risk of collapse of the mining entry and pillar. This is influenced by the stability factor of the opening hole and also the pillar as a natural buffer in the mining area. Given these problems, a geotechnical study of the design of underground coal pillars is needed so that mining activities can be carried out safely and smoothly. Chain pillar stability analysis using the traditional methods of Obert and Duvall (1967), and Bienawski (1983). Determination of chain pillar width design was analyzed analytically. Seam geometry data seam $D=9 \mathrm{~m}$, then the extraction ratio is $43.75 \%$ at one mining level. If based on the calculation of the critical width of the chain pillar for each level, the extraction ratio value is, seam $D=5.94 \mathrm{~m}$, the value of $r=55.85$ $\%$ is obtained.

*Penulis Koresponden: rhkputri@itats.ac.id

Doi : https://doi.org/10.36986/impj.v2i1.21 


\section{PENDAHULUAN}

Penambangan batubara dengan metode shortwall memiliki resiko terhadap keruntuhan atap lubang bukaan dan pilar batubara. Hal ini dipengaruhi oleh faktor kestabilan dari lubang bukaan dan juga pilar tersebut sebagai penyangga alamiah pada area penambangan. Dengan adanya permasalahan tersebut diperlukan suatu kajian geoteknik terhadap rancangan pilar batubara bawah tanah, agar kegiatan penambangan dapat dikerjakan dengan aman dan lancar. Penentuan desain lebar chain pillar dianalisis secara analitik.

\section{TINJAUAN PUSTAKA}

\section{Pembebanan Pillar}

Pada tambang batubara bawah tanah ada dua jenis kondisi pembebanan. Dalam penambangan room and pillar, pembebanan pada chain pillar berada di tengah dari development heading (baris 6 dan 7 pada Gambar 3.22). Diatur oleh apa yang disebut konsep pembebanan tributary area (Gambar 3.20). Dalam konsep ini daerah yang didukung oleh pillar meliputi daerah di atasnya dan daerah tributary area itu (Obert dan Duvall, 1967). Dengan kata lain, pillar menyangga dengan seragam beban dari perlapisan batuan pillar serta satu-setengah lebar entry di setiap sisi pillar .

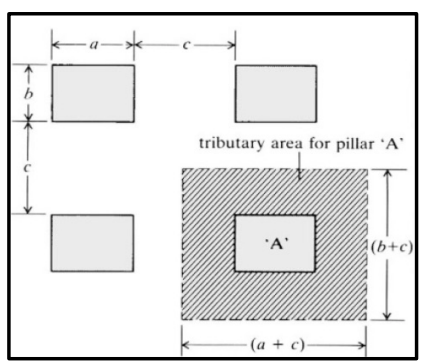

Gambar 1

Tributary Area (Obert and Duval,1967) $r=[(a+c)(b+c)-a b] /(a+c)(b+c)$

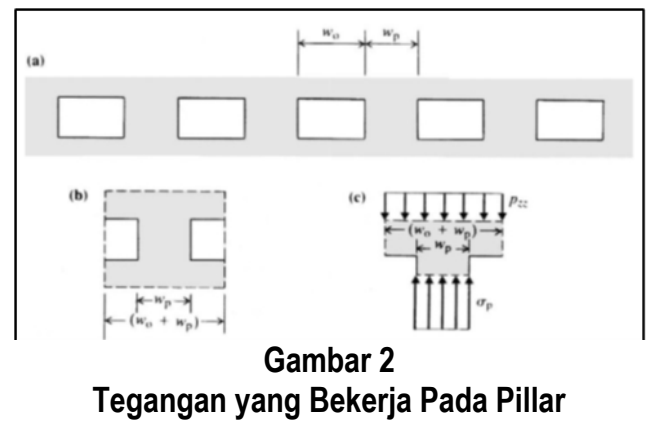

Jadi dalam tata letak room and pillar tegangan ratarata pillar adalah (Gambar 3.2) untuk pillar persegi.

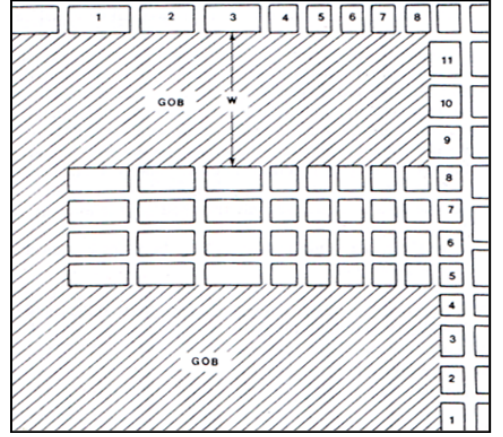

Gambar 3.2.

Kondisi pembebanan pillar (Obert dan Duvall, 1967)

Sedang tegangan rata-rata pillar dirumuskan :

$\frac{P}{W_{p}^{2}}=\frac{\left(W_{o}+W_{p}\right)^{2} \gamma \cdot h}{W_{p}^{2}}$

(3.1)

$\sigma_{a}=\left(1+\frac{W_{o}}{L_{p}}\right)\left(1+\frac{W_{o}}{W_{p}}\right) \cdot \sigma_{v}$

Dimana $\sigma a=P / W p^{2}$ adalah tegangan rata-rata pillar, $\mathrm{P}$ adalah beban total pada pillar, Wp dan Wo adalah lebar dari pillar dan rooms atau entries, $\sigma v=\gamma \mathrm{h}$ adalah tegangan vertikal, $\mathrm{y}$ adalah bobot isi dari batuan, dan $\mathrm{h}$ adalah kedalaman dibawah permukaan (Gambar 3.2).

\section{Kekuatan Pillar}

Kekuatan pillar batubara tergantung pada ukuran dan bentuk dari spesimen yang diuji. Hubungan itu akan didiskusikan pada bagian ini.

\section{Efek Ukuran (Size Effect)}

Kekuatan batubara dapat ditentukan dari laboratorium dan uji in-situ. Kekuatan batubara yang diperoleh dari uji laboratorium biasanya lebih besar ketika ukuran spesimen makin kecil. Hal ini menunjukan fakta bahwa umumnya semakin besar ukuran spesimen, maka makin banyak kekar dan atau fractures, itu menunjukan hasil kekuatan yang lebih kecil. Uji kekuatan in-situ dari pillar bawah tanah, dapat menghilangkan atau mengurangi masalah ukuran dan hasilnya lebih mewakili, tetapi itu sangat mahal dan memakan waktu. Oleh karena itu memerlukan usaha yang lebih untuk memprediksi kekuatan in-situ pillar dari hasil uji laboratorium. Hubungan antara ukuran dan kekuatan dari spesimen dapat digeneralisasikan oleh persamaan (Evans et al., 1961).

$$
S_{1}=k_{1} d^{-a}
$$


dimana $S_{1}$ adalah Uniaxial compressive strength dari kubikal pillar, $d$ adalah panjang sisi dari spesimen, dan $k_{1}$ dan a adalah konstanta. Nilai dari konstanta a mulai dari 0,38 sampai 0,66 (Peng, 1978), dengan rata-rata 0,5. Bieniawski (1969) menunjukkan beberapa rangkaian dari uji in-situ dan menemukan bahwa untuk kubikal spesimen, kekuatan menurun dengan bertambahnya ukuran spesimen dan menjadi konstan ketika mencapai ukuran kritis spesimen kurang lebih $5 \mathrm{ft}$ untuk batubara. Ini berarti kekuatan kritis dari spesimen dapat mewakili dari kekuatan insitu pillar batubara.

Pendekatan lain untuk ekstrapolasi kekuatan batubara dari kekuatan di laboratorium ke in-situ strength dapat dinyatakan oleh persamaan (Hustrulid, 1976):

$$
S_{1}=\frac{k_{1}}{\sqrt{36}}
$$

atau

$$
S_{1}=\frac{k_{1}}{\sqrt{H}}
$$

Persamaan 3.4 digunakan ketika tinggi $\mathrm{H}$ lebih besar dari 36 in. jika tidak menggunakan persamaan 3.5

\section{Efek Bentuk (Shape Effect)}

Pada penambahan efek ukuran, kekuatan batubara juga tergantung pada geometri spesimen dan efek bentuk. Bahwa rasio dari diameter atau lebar dan tinggi dari spesimen (Evans et al., 1961; Obert dan Duvall, 1967). Banyak perumusan kekuatan pillar rata-rata puncak itu telah memperkenalkan efek bentuk. Hal tersebut dapat dikelompokan kedalam dua tipe, yaitu :

$$
S_{2}=S_{1}\left(A+B \frac{W_{p}}{H}\right)
$$

dan

$$
S_{2}=S_{1} \frac{W_{p}^{\alpha}}{H^{\beta}}
$$

dimana $S_{2}$ adalah kekuatan pillar dan akibat efek bentuk, $S_{1}$ adalah UCS dari kubikal pillar yang diperoleh dari persamaan 3.3, 3.4, dan 3.5, $A, B, \alpha, \beta$ adalah konstanta yang tergantung pada karakteristik dari seam batubara, $W_{p}$ adalah lebar pillar, dan $H$ adalah tinggi pillar. Tinggi pillar, $H$ biasanya tinggi seam, kekuatan pillar $S_{2}$ ditentukan oleh lebar itu.

Berdasarkan Bieniawski (1983), dari semua rumusan kekuatan pillar yang

tersedia, Persamaan yang disebut dibawah ini relevan untuk diaplikasikan pada penambangan batubara U.S.:
1. Rumusan Obert-Duvall (Obert and Duvall, 1967)

$$
S_{2}=S_{1}\left(0,778+0,222 \frac{W_{p}}{H}\right)
$$

2. Rumusan Holland (Holland, 1964)

$$
S_{2}=S_{1} \sqrt{\frac{W_{p}}{H}}
$$

3. Rumusan Holland-Gaddy (Gaddy, 1956)

$$
S_{2}=k_{1} \frac{\sqrt{W_{p}}}{H}
$$

4. Rumusan Salamon-Munro (Salamon and Munro 1967)

$$
S_{2}=\frac{k_{1} W_{p}^{0,46}}{12 H^{0,66}}
$$

5. Rumusan Bieniawski (1983)

$$
S_{2}=S_{1}\left(0,64+0,36 \frac{W_{p}}{H}\right)
$$

Hubungan antara bentuk dan kekuatan percontoh dapat dituliskan :

$$
S_{2}=S_{1}\left(A+B \frac{W_{p}}{H}\right)
$$

\section{Metode Rancangan Chain Pillar Tradisional}

Dalam metode tradisional ini, desain ukuran pillar ditentukan dengan menjumlahkan pillar yang termuat pada kekuatan pillar tanpa menggunakan efek distribusi tekanan nyata pada pillar dan interaksi sebagian atap, endapan dan pillar. Menurut Obert dan Duvall (1967), rancangan pillar tradisional untuk penambangan dimulai dengan menaksir tegangan vertikal insitu $\left(\sigma_{v}\right)$, ditunjukkan dengan rumus :

$$
\left(\sigma_{v}\right)=\gamma h
$$

Dengan:

$$
\begin{aligned}
& \sigma_{v}=\text { tegangan vertikal insitu }\left(\mathrm{kg} / \mathrm{m}^{2}\right) \\
& \gamma=\text { berat jenis batuan }\left(\mathrm{kg} / \mathrm{m}^{3}\right) \\
& h \quad=\text { kedalaman penambangan dari permukaan } \\
& \operatorname{tanah}(\mathrm{m})
\end{aligned}
$$

Sedang tegangan rata-rata pillar dirumuskan :

$$
\frac{P}{W_{p}^{2}}=\frac{\left(W_{o}+W_{p}\right)^{2} \gamma \cdot h}{W_{p}^{2}}
$$


$\sigma_{a}=\left(1+\frac{W_{o}}{L_{p}}\right)\left(1+\frac{W_{o}}{W_{p}}\right) \cdot \sigma_{v}$

Dengan:

$\mathrm{P}=$ total beban pillar $(\mathrm{kg})$

$\sigma_{a}=$ tegangan rata-rata pillar $\left(\mathrm{kg} / \mathrm{m}^{2}\right)$

$\mathrm{W}_{\mathrm{o}}=$ lebar room $/$ bukaan $(\mathrm{m})$

$\mathrm{W}_{\mathrm{p}}=$ lebar pillar $(\mathrm{m})$

$\mathrm{L}_{p}=$ panjang pillar $(\mathrm{m})$

Kekuatan pillar didasarkan pada ukuran dan bentuk percontoh yang dilakukan uji laboratorium. Hubungan antara ukuran dan kekuatan percontoh menurut Obert dan Duvall (1967) dapat dituliskan :

$$
\mathrm{S}_{1}=\frac{\sigma_{c}}{5}
$$

dengan :

$\mathrm{S}_{1}=$ kekuatan kompresif uniaksial dari pillar $\left(\mathrm{kg} / \mathrm{m}^{2}\right)$ $\sigma_{c}=$ kuat tekan uniaksial $\left(\mathrm{kg} / \mathrm{m}^{2}\right)$

Hubungan antara bentuk dan kekuatan percontoh dapat dituliskan :

(3.18)

$$
\mathrm{S}_{2}=S_{1}\left(A+B \frac{W_{p}}{H}\right)
$$

dengan :

$\mathrm{S}_{2}=$ kekuatan pillar yang memperhitungkan bentuk pillamya $\left(\mathrm{kg} / \mathrm{m}^{2}\right)$

$\mathrm{S}_{1}=$ kekuatan kompresif uniaksial dari pillar $\left(\mathrm{kg} / \mathrm{m}^{2}\right)$ $\mathrm{A}$ dan $\mathrm{B}=$ konstanta berdasarkan karakteristik endapan

$\mathrm{H}=$ tinggi endapan yang ditambang $(\mathrm{m})$

$\mathrm{W}_{\mathrm{p}}=$ lebar pillar $(\mathrm{m})$

Untuk menghitung $\mathrm{S}_{2}$, digunakan rumus Bienieawski (1983) :

$$
\mathrm{S}_{2}=S_{1}\left(0.64+0.36 \frac{W_{p}}{H}\right)
$$

Sehingga perhitungan pillar yang termuat pada kekuatan kekuatan pillar menjadi :

$$
\frac{\left(W_{o}+W_{p}\right)^{2} \cdot \sigma_{y}}{W_{p}^{2}}=S_{1}\left(A+B \frac{W_{p}}{H}\right)
$$

Kemudian diubah dalam satu ruas :

$B \cdot S_{1} \cdot W_{p}^{3}+\left(A \cdot S_{1}-\sigma_{v}\right) W_{p}^{2}-2 \cdot \sigma_{v} \cdot W_{o} \cdot W_{p}-W_{o}^{2} \cdot \sigma_{v}=0$

Dijabarkan :

$$
\begin{aligned}
& a=\frac{\left(A S_{1}-\gamma h\right) H}{B S_{1}} \\
& b=\frac{-2 \gamma h W_{o} H}{B S_{1}} \\
& c=\frac{-W_{o}^{2} \gamma h H}{B S_{1}} \\
& Q=\frac{3 b-a^{2}}{9} \\
& R=\frac{9 a b-27 c-2 a^{3}}{54} \\
& U=\sqrt[3]{R+\sqrt{Q^{3}+R^{2}}} \\
& T=\sqrt[3]{R-\sqrt{Q^{3}+R^{2}}}
\end{aligned}
$$

dimana $\gamma=\rho g$

dengan pembeda, jika $D>0\left(D=Q^{3}+R^{2}\right)$

maka $W_{p}=U+T-\frac{1}{3} a$

Jika $\mathrm{D}<0$ maka $W_{p}=2 \sqrt{-Q} \cos \left(\frac{\theta}{3}\right)-\frac{1}{3} a$

dengan $\cos \theta=R / \sqrt{-Q^{3}}$

Jadi total beban $(\mathrm{P})$ dapat dihitung dengan rumus :

$$
P=\left(W_{0}+W p\right)^{2} \sigma_{v}
$$

Untuk mengetahui faktor keamanan dari rancangan perlu diketahui dahulu tegangan rata-rata (бa) , dihitung dengan rumus :

(3.25)

$$
\sigma a=\left(P / W^{2}\right) \times 9,80665 \times 10^{-6}
$$

Sehingga faktor keamanannya (FK) :

$\mathrm{FK}=\mathrm{S}_{2} / \sigma_{a}$

Dan tinggi runtuh yang mungkin terjadi dihitung dengan rumus :

Tinggi runtuh $=\frac{100-R M R}{100} \times W_{o}$

dengan RMR = hasil pembobotan massa batuan.

\section{HASIL DAN PEMBAHASAN}

Tabel 1 Material Properties Batuan Utuh (Intack Rock) 


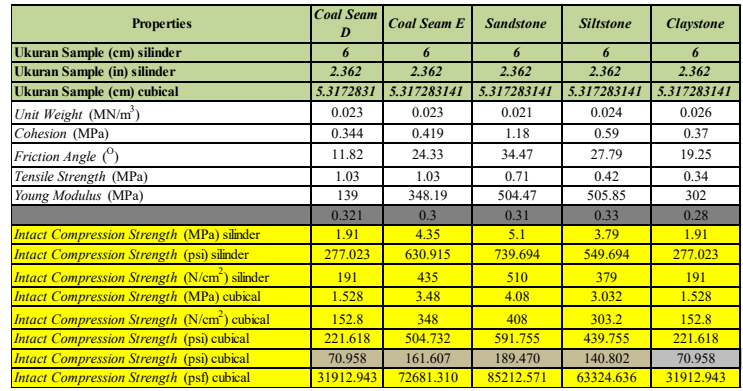

(Sumber : Penelitian, 2019)

Kegiatan pemboran geoteknik dilakukan untuk keperluan analisis geoteknik dan mendapatkan parameter masukan dalam menganalisis kestabilan lubang bukaan dan pilar. Pengambilan sejumlah sampel yang diuji dilaboratorium dipilih berdasarkan keterwakilan dalam masing-masing lubang bor. Sampel geoteknik sebelumnya yang telah diambil merupakan perwakilan dari sampel titik bor BAL, AP dan AUG. Pengujian yang dilakukan meliputi pengujian sifat fisik (Natural water content, Spesific gravity, Unit weight natural state, Dry unit weight, Degree saturation, Natural porosity, Natural Void ratio, Atterbarg Limits, dan Hydrometer), dan pengujian sifat mekanik (Consolidation, Permeability, Direct Shear, Tensile Strength, Unconfined Comp. Strength, Point Load dan Triaxial Comp. Strength). Hasil pengujian ini merupakan data sekunder dilapangan yang diuji oleh pihak ketiga sehingga diperoleh hasil sebagai betikut (Tabel 4.1) :

\section{Perbandingan dari Persamaan Kekuatan Pilar}

Terdapat lima persamaan kekuatan pilar yang telah diterapkan secara luas pada tambang bawah tanah batubara. Batubara yang digunakan pada daerah penelitian Airlaya memiliki nilai $k=425,75$ yang akan digunakan pada persamaan (3.12). Dengan demikian besar kekuatan batubara insitu seam Airlaya diperkirakan 161,607 psi. Berdasarkan lima persamaan kekuatan pilar, besar kekuatan pilar batubara dari seam Airlaya hanya akan menggunakan Formula Bienawski antara lain :

\section{Bieniawski Formula}

$$
\sigma_{p}=161,607\left[0,64+0,36\left(\frac{w}{h}\right)\right]
$$

Analisis Kestabilan Chain Pillar

Rancangan desain pilar yang digunakan untuk menambang batubara berdasarkan perhitungan untuk metode rancangan chain pillar tradisional. Dalam metode ini, desain ukuran pilar ditentukan dengan menjumlahkan pilar yang termuat pada kekuatan pilar tanpa menggunakan efek distribusi tekanan nyata pada pilar dan interaksi sebagian atap, endapan dan pilar. Perancangan chain pillar menurut Obert dan Duvall (1967) dan Bienieawski (1983) dengan metode tradisional.

Analisis kestabilan chain pillar dilakukan pada dua level penambangan dengan menggunakan seam batubara tiap level yang paling dalam. Perhitungan chain pillar per level penambangan dapat dijabarkan pada Tabel 4.5 - Tabel 4.8.

\section{Perhitungan Chain pillar seam D}

Data masukan untuk perhitungan chain pillar adalah sebagai berikut :

- Kedalaman penambangan (h) : $365 \mathrm{~m}$

- Tinggi penambangan $(H): 2,45 \mathrm{~m}$

- Lebar entry (Wo) : $3 \mathrm{~m}$

- Berat jenis batuan (y): $2.230,38 \mathrm{~kg} / \mathrm{m}^{3}$

- Rock Mass Rating (RMR) : 65

- UCS Batubara : $6.101 .100 \mathrm{~kg} / \mathrm{m}^{2}$

- Konstanta batuan (A) : 0,64

- Konstanta batuan (B) : 0,36

Perhitungan chain pillar pada seam $D$ adalah :

- Tegangan vertikal insitu $\left(\sigma_{v}\right)$

$$
\begin{aligned}
\left(\sigma_{v}\right) & =\gamma \mathrm{h} \\
& =(2.230,38)(365) \\
& =814.090,38 \mathrm{~kg} / \mathrm{m}^{2}
\end{aligned}
$$

- Kekuatan kompresif uniaksial pillar $\left(\mathrm{S}_{1}\right)$

$$
\begin{aligned}
S_{1} & =\frac{\sigma_{c}}{5} \\
& =(6.101 .100) / 5 \\
& =1.220 .220 \mathrm{~kg} / \mathrm{m}^{2}
\end{aligned}
$$

- $\quad B \cdot S_{1} \cdot W_{p}{ }^{3}+\left(A \cdot S_{1}-\sigma_{v}\right) W_{p}{ }^{2}-2 \cdot \sigma_{v} \cdot W_{o} \cdot W_{p}-W_{o}{ }^{2} \cdot \sigma_{v}=0$

$(0,36)(1.220 .220)\left(W_{p}{ }^{3}\right)+\left(0,64^{*} 1.220 .220-814.090,38\right) W_{p}{ }^{2}$

$\left(2^{\star} 814.090,38^{*} 3\right) W_{p}-\left(3^{2} 814.090,38\right)=0$

- $a=\frac{\left(A S_{1}-\gamma h\right) H}{B S_{1}}$

$$
\begin{aligned}
& a=\frac{(0,64 * 1.220 .220-2.230,38 * 365) 2,45}{0,36 * 1.220 .220} \\
= & -0,18 \\
b= & \frac{-2 \gamma h W_{o} H}{B S_{1}} \\
b & =\frac{-2 * 2.230,38 * 365 * 3 * 2,45}{0,36 * 1.220 .220}
\end{aligned}
$$




$$
\begin{gathered}
=-27,24 \\
c=\frac{-W_{o}^{2} h h H}{B S_{1}} \\
c=\frac{-(3)^{2} * 2.230,38 * 365 * 2,45}{0,36 * 1.220 .220}=-
\end{gathered}
$$

40,86

$$
\begin{aligned}
Q & =\frac{3 b-a^{2}}{9} \\
& Q=\frac{3(-27,24)-(-0,18)^{2}}{9}=-9,08 \\
\text { - } \quad R & =\frac{9 a b-27 c-2 a^{3}}{54} \\
R & =\frac{9(-0,18)(-27,24)-27(-40,86)-2(-0,18)^{3}}{54}
\end{aligned}
$$$$
=21,27
$$

- $U=\sqrt[3]{R+\sqrt{Q^{3}+R^{2}}}$

$$
U=\sqrt[3]{21,27+\sqrt{(-9,08)^{3}+(21,27)^{2}}}=-
$$

42,46

- $\quad T=\sqrt[3]{R-\sqrt{Q^{3}+R^{2}}}$

$$
T=\sqrt[3]{21,27-\sqrt{(-9,08)^{3}+(21,27)^{2}}}=56,64
$$

- $\mathrm{D}=\mathrm{Q}^{3}+\mathrm{R}^{2}$

$$
\mathrm{D}=(-9,08)^{3}+(21,27)^{2}=-297,29
$$

- $\cos \theta=R / \sqrt{-Q^{3}}$

$$
\begin{aligned}
\cos \theta & =21,27 / \sqrt{-(-9,08)^{3}} \\
\theta & =39,03^{\circ}
\end{aligned}
$$

- JikaD<0maka $W_{p}=2 \sqrt{-Q} \cos \left(\frac{\theta}{3}\right)-\frac{1}{3} a$

$$
W_{p}=2 \sqrt{-(-9,08)} \cos \left(\frac{39,03}{3}\right)-\frac{1}{3}(-0,18)=5,94
$$

$\mathrm{m}$

- Kekuatan Pillar berdasarkan bentuk pillamya $\left(S_{2}\right)$

$$
\mathrm{S}_{2}=S_{1}\left(0.64+0.36 \frac{W_{p}}{H}\right)
$$

$$
\begin{aligned}
\mathrm{S}_{2} & =1.220 .220\left(0.64+0.36 \frac{9}{2,45}\right) \\
\mathrm{S}_{2} & =2.394 .619,49 \mathrm{~kg} / \mathrm{m}^{2} \\
& \bullet \quad \text { Total beban }(\mathrm{P}) \\
\mathrm{P}= & (\mathrm{Wo}+\mathrm{Wp})^{2} \sigma_{v} \\
\mathrm{P} & =(3+9)^{2}(814.090,38) \\
= & 117.229 .015,38 \mathrm{~kg} \\
& \bullet \quad \text { Tegangan rata-rata }(\sigma a) \\
\sigma a & =\left(\mathrm{P} / \mathrm{W}^{2}\right) \times 9,80665 \times 10^{-6} \\
\sigma a & =\left(\left(117.229 .015,38 /(9)^{2}\right) \times 9,80665 \times 10-6\right. \\
= & 1.447 .271,79 \mathrm{~kg} / \mathrm{m}^{2}
\end{aligned}
$$

- Faktor Keamanan (FK)

$\mathrm{FK}=\mathrm{S}_{2} / \sigma_{a}$

$$
\mathrm{FK}=(2.394 .619,49) /(1.447 .271,79)=1,65
$$

(FK $>1,3$ Kategori Aman)

- $\quad$ Tinggi runtuh $=\frac{100-R M R}{100} \times W_{o}$

- Tinggi runtuh $=\frac{100-65}{100} \times 3=1,05 \mathrm{~m}$

\section{Kajian Kestabilan Pillar}

Pillar merupakan sebagian dari batubara yang disisakan pada proses penambangan. Pillar difungsikan sebagai penyangga alamiah untuk meningkatkan faktor keamanan pada bukaan tambang bawah tanah. Nilai faktor yang digunakan sebagai acuan keamanan menurut Hoek. E, Kaiser. P.K, dan Bawden.W.F., 1993. Untuk keadaan aman nilai FK > 1,3 untuk pillar kategori aman.

Chain pillar merupakan pillar batubara yang disisakan antara main gate dan tail gate pada sistem panel. Pada rancangan penambangan PT. Bukit Asam, Tbk (Persero) ditetapkan lebar chain pillar sebesar $9 \mathrm{~m}$ untuk tiap level penambangan. Analisi kestabilan chain pillar mengacu pada rumusan Obert dan Duvall (1967), dan Bienieawski (1983) dengan metode tradisional. Hasil analisis menghasilkan rekomendasi lebar chain pillar (Wp) dan nilai faktor keamanan (FK). Pada level penambangan seam $D$, lebar chain pillar $(\mathrm{Wp})$ minimum 5,94 $\mathrm{m}$ dengan yang digunakan yaitu $9 \mathrm{~m}$. Nilai FK yang didapat adalah 1,65 dikategorikan Aman (FK > 1,3)

Batubara yang disisakan sebagai pillar akan ditinggalkan, dan apabila secara geoteknik memungkinkan dapat dilakukan pillar robing (peruntuhan pillar) yang akan berpengaruh terhadap 
rasio ekstraksi pada batubara. Sesuai dengan Gambar 3.1, maka rasio ekstraksi dapat dirumuskan (Gambar 3.1Tributary Area )sebagai berikut :

Berdasarkan geometri lebar chain pillar yang digunakan oleh PT.Bukit Asam, Tbk (Persero)sebesar $9 \mathrm{~m}$, dengan data geometri seam $\mathrm{D}=9 \mathrm{~m}$, maka didapat ekstraksi rasio sebesar $43,75 \%$ pada satu level penambangan. Jika berdasarkan hasil perhitungan lebar kritis chain pillar tiap levelnya didapat nilai ekstraksi rasio yaitu, seam $\mathrm{D}=5,94 \mathrm{~m}$, didapat nilai $\mathrm{r}=$ $55,85 \%$.

\section{KESIMPULAN DAN SARAN}

\section{Kesimpulan}

Kesimpulan dari hasil rencana desain dan stabilitas pilar pada seam Airlaya adalah sebagai beriku:

Berdasarkan hasil analisis persamaan kekuatan pilar, persamaan Bieniawski memprediksi nilai kekuatan pilar tertinggi pada kondisi seam Airlaya sehingga diperoleh persamaan kekuatan seam Airlaya adalah $\sigma p=161,607[A+B(w / h)]$.

Pada kondisi seam Airlaya yang memiliki kedalaman lebih dari $500 \mathrm{ft}$, sehingga persamaan kekuatan pilar yang cocok digunakan untuk memprediksi nilai kekuatan pilat adalah persamaan Bieniawski dan Obert-Duvall.

Pilar yang direkomendasikan berbentuk rectangular dengan dimensi lebar 9 meter. maka didapat ekstraksi rasio sebesar $43,75 \%$ pada satu level penambangan. Jika berdasarkan hasil perhitungan lebar kritis chain pillar tiap levelnya didapat nilai ekstraksi rasio yaitu, seam $\mathrm{C}=5,94$ m, didapat nilai $r=55,85 \%$.

\section{Saran}

Saran yang diperoleh dari rencana desain dan stabilitas pilar adalah sebagai berikut:

1. Diperlukan lebih pengujian perpercontohh dengan berbagai ratio $\mathrm{w} / \mathrm{h}$ sehingga data yang didapatkan lebih informatif dalam penentuan dimensi pilar agar nilai ekstrasi batubara lebih besar.

2. Adanya penelitian lebih lanjut mengenai tegangan abutment baik di area pilar maupun di area panel

3. Diperlukan proses validasi lanjut untuk secara empirik untuk memastikan hasil penelitian ini dengan konsidi serupa dengan seam Airlaya sebagai dasar pertimbangan dalam rencana desain pilar.

\section{UCAPAN TERIMA KASIH}

Ucapan Terima Kasih kepada Manajemen PT. Bukit Asam, Tbk (Persero)

\section{DAFTAR PUSTAKA}

Anonim 1, 1999, "Teknologi Pertambangan Batubara Program Pertukaran Teknisi", New Energy and Industrial Technology Development Organization (NEDO), Japan Coal, Jepang.

Anonim 2, 2000, "Teknologi Pertambangan Batubara Program Pertukaran Teknisi", New Energy and Industrial Technology Development Organization (NEDO), Japan Coal, Jepang.

Bienawski ZT (1968). The effect of specimen size on compressive strength of coal. Int. J. Rock Mech. Min. Sci. Geomech. Abstr.5(4): 325-326, IN5-IN10, 327-335. DOI: 10.1016/0148-962(68)90004-1.

Bieniawski ZT, VN hwl (1975). The significance of insitu test on Exploration Rock Eng. Proc. Symp. (ed. Z.T. Bieniawski) 1. Cape Town, Balkema. Pp.97106

Bieniawski, Z. T.1984."Rock Mechanics Design in Mining and Tunneling".A.A. Balkema. Boston.

Hoek, E., Kaiser, P.K. and Bawden. W. F. 1995. Support of underground excavations in hard rock. Rotterdam : Balkema.

Hustrulid WA (1976). A review of coal pillar strength formulas. Rock Mech. Rock Eng. 8(2):115-145, DOI: 10.1007/BF01239762.

Mark C (1990). Pillar Design Methods for Longwall Mining. USBM IC 9247, 53 p.

Mark C (1992). Analysis of Longwall Pillar Stability (ALPS)--An Update. Proceedings, Workshop on Coal Pillar Mechanics and Design, USBM IC 9315, pp. 238-249.

Mark C (1999). Empirical Methods for Coal Pillar Design. Proceedings, 2nd International Workshop on Coal Pillar Mechanics and Design, Vail, CO, NIOSH IC 9448, pp. 145-154.

Molinda GM and Mark C (1994). The Coal Mine Roof Rating (CMRR): A Practical Guide for Rock Mass Classification in Coal Mines. USBM IC 9387, 83 p.

Obert L, Duvall WI (1967). Rock Mechanics and the Design of Structures in Rock, John Wiley \& Sons Inc. New York pp. 542-545

Peng, S. S., 1986, "Coal Mine Ground Control", John Wiley \& Sons, Inc., New York, U.S.A.

Peng, S, S. and Chiang, H, S., 1984, "Longwall Mining", John Wiley \& Sons, Inc., New York, U.S.A. 
Indonesian Mining Professionals Journal Volume 2, Nomor 2, April 2020 : 43-50 